\title{
Childhood Pneumonia in Low and Middle Income Countries: Burden, Prevention and Management
}

\author{
D. Gray* and H.J. Zar
}

\author{
Department of Pulmonology, School of Child and Adolescent Health, Red Cross War Memorial Children's Hospital, \\ University of Cape Town, South Africa
}

\begin{abstract}
Background: Pneumonia is the leading cause of morbidity and mortality in children under five years of age worldwide. The burden of childhood pneumonia occurs predominantly in low or middle income countries. Despite recent advances in management and preventative strategies, high rates of treatment failure and case fatality continue to occur in children in such countries.

Aim: To review the current evidence on the epidemiology and management of childhood pneumonia in low and middle income countries

Methods: Direct search of Medline database from 1995 to date through Pubmed was conducted. Search terms included: (pneumonia OR lower respiratory tract infections OR lower respiratory infections OR ARI) AND child. Search was restricted to English articles. In addition reference lists of selected studies were reviewed for relevant information.

Findings: Major findings accounting for the high burden include delayed health seeking, poor access to health care, poorly resourced health care systems, inadequate immunisation programs and lack of availability of oxygen delivery systems. The burden of pneumonia deaths has also been increased by the paediatric HIV epidemic in sub-Saharan Africa. Effective preventive interventions include exclusive breastfeeding, optimizing nutrition, reduction of indoor air pollution and immunisations. Wider availability of new immunisations particularly pneumococcal conjugate vaccine can substantially reduce pneumonia incidence. Prophylactic trimethoprim- sulphamethoxazole and antiretroviral therapy are important strategies to prevent pneumonia in HIV infected children, and wider implementation of these is still needed. The most effective treatment strategy remains case management guidelines as contained in the Integrated Management of Childhood Illness program. Case management efficacy is dependent on timely access to health facilities, on health worker ability to recognise and treat pneumonia or severe pneumonia and on availability of appropriate antibiotics and functioning referral pathways. In areas of high HIV prevalence, guidelines must be adapted to broaden antimicrobial coverage including treatment for Pneumocystis jirovecii pneumonia. Monitoring of hypoxia with pulse oximetry and appropriate oxygen delivery systems are still not widely available and should be prioritized in pneumonia management programs.

Conclusions: Improved access to preventive and management strategies is urgently needed to reduce the burden of childhood pneumonia in resource limited settings. Further research on childhood pneumonia is needed to delineate the burden of specific pathogens, to develop better diagnostic tests and to improve current management and preventive strategies.
\end{abstract}

Keywords: Pneumonia, children, burden, prevention, management.

\section{BURDEN OF CHILDHOOD PNEUMONIA}

Pneumonia remains the leading cause of death in children under 5 years in low and middle income countries despite the introduction of case management guidelines and the development of new preventative strategies including effective vaccines [1]. Pneumonia currently accounts for $18 \%$ of annual deaths in children under five worldwide, $20 \%$ in low income countries compared to only $4.3 \%$ in high income countries [1]. The global incidence of clinical pneumonia cases has been estimated to be 0.29 events per child year, which equates to 150 million new episodes

*Address correspondence to this author at the Department of Pulmonology, School of Child and Adolescent Health, Red Cross War Memorial Children's Hospital, University of Cape Town, South Africa; Tel: +27 21658 5001; Fax: +27 21658 5530; E-mail: diane.gray@uct.ac.za annually worldwide [2]. The burden of childhood pneumonia remains disproportionately represented in low and middle income countries; $74 \%$ of new pneumonia cases occur in just 15 countries and more than half in just 6 countries: India, China, Pakistan, Bangladesh, Indonesia and Nigeria [3]. The estimated clinical pneumonia incidence expressed as events per child year is highest in South East Asia (0.36), then Africa (0.33), followed by the Eastern Mediterranean (0.28) [3]. In addition severe pneumonia requiring hospitalization makes up a significant proportion of these pneumonia episodes, accounting for $7-13 \%$ of cases [3]. Severe respiratory infections in childhood may be associated with an increase in long term respiratory morbidity and an added health burden [4-6].

Childhood pneumonia is caused by a combination of host and environmental factors. In low and middle income 
countries pneumonia is frequently caused by bacterial pathogens, in contrast to high income countries where viral pathogens predominate. The main bacterial causes of childhood pneumonia are Streptococcus pneumoniae (pneumococcus) and Haemophilus influenzae [7-10]. Pneumococcal disease is the most common cause of vaccine preventable deaths [11]. In 2000 there were an estimated 13.8 million cases of pneumococcal pneumonia, causing 741000 deaths in children under 5 years, 82700 in HIV positive and 658000 in HIV negative children. Most cases of pneumococcal pneumonia occurred in South East Asia (38.6\%), Africa (27.6\%) and the Western Pacific region (17\%) [11]. Similarly $H$. influenzae type $b$ (Hib) infection, still contributes substantially to the global burden of childhood pneumonia; recent estimates are 7.9 million cases of $\mathrm{H}$ influenzae pneumonia annually in children under 5 years worldwide, causing 292000 deaths, 6400 in HIV positive children and 286000 in HIV negative children [12]. An important cause of bacteraemic pneumonia in tropical Africa is non-typhoidal salmonellae [13-15]; this is not treated by current recommended first line antibiotic for childhood pneumonia [16]. The main viral cause of childhood pneumonia in children admitted to a rural Kenyan hospital was respiratory syncytial virus (RSV), with Human coronavius, influenza type A, Parainfluenza type 3, Human adenovirus and human metapneumonvirus being less frequent but important pathogens ${ }^{1}$. RSV was associated with severe disease ${ }^{1}$. Childhood pneumonia is frequently caused by multiple pathogens - these include combinations of bacterial, viral, mycobacterial or fungal infections. Recent studies have shown that prognosis is exponentially worse as the number of causative pathogens increases [17].

The HIV epidemic has increased the burden of childhood pneumonia in high HIV prevalence areas. Paediatric HIV is essentially a disease of children in sub-Saharan Africa where more than $90 \%$ of the approximately 2 million HIV-infected children under 15 years reside [18]. Pneumonia is the commonest cause of hospitalization and death in HIVinfected children [17, 19-21]. Pneumonia related mortality is 6 fold higher in HIV infected compared to HIV uninfected children $^{2}$. Increasing evidence suggests that HIV exposed uninfected children also have a higher risk of severe pneumonia and poorer outcome as compared to HIV unexposed infants [17]. In addition, there has been an exponential increase in tuberculosis (TB) prevalence in areas of high HIV prevalence. In the WHO African region TB incidence has increased from 168 per 100000 population per year in 1990 to 363 cases per 100000 population per year in $1997^{3}$. Tuberculosis contributes to the burden of acute and chronic lung disease in children.

Prioritizing the prevention and appropriate management of childhood pneumonia is essential to meet the Millennium Development Goal 4 of decreasing under 5 child mortality by two thirds from 1995 by 2015 . In response to this the

${ }^{1}$ Berkley JA, Munywoki P, Ngama Mwanajuma, et al. Viral etiology of severe pneumonia among Kenyan infants and children JAMA 2010; 303(20): 2051-7.

${ }^{2}$ Enarson PM, Gie RP, Enarson DA, et al. Impact of HIV on standard case management for severe pneumonia in children Expert Rev Respir Med 2010; 4(2): 211-20

${ }^{3}$ WHO: World Health Statistics. Geneva. In.; 2009.
WHO and UNICEF have developed the Global Action Plan for Prevention and Control of Pneumonia (GAPP) to highlight pneumonia as a major cause of death in children and to assist in scaling up of interventions with proven benefit [22].

\section{PREVENTION OF CHILDHOOD PNEUMONIA}

All children should be protected against pneumonia through promoting a healthy environment and access to effective preventive and treatment measures. Strategies for reducing childhood pneumonia (Table 1) include.

Table 1. Prevention Strategies for Childhood Pneumonia

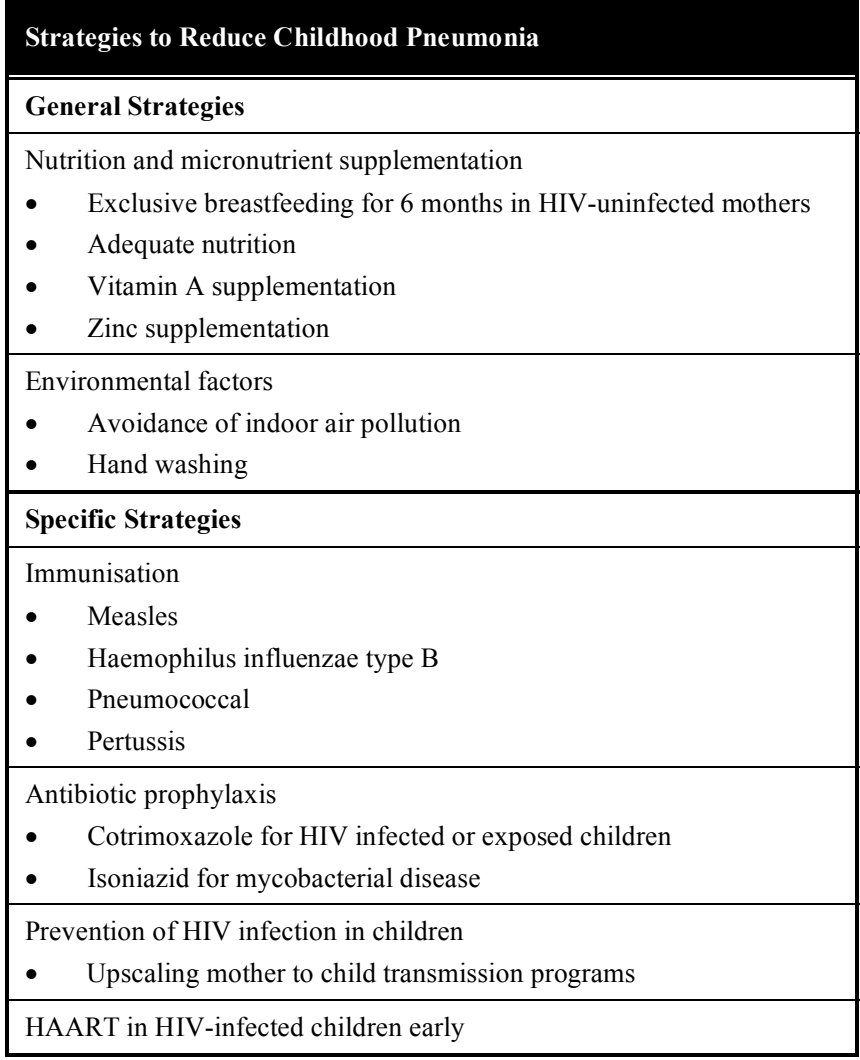

\section{Nutritional Interventions}

\section{Exclusive Breastfeeding}

Exclusive breastfeeding for the first 6 months of life and continued from 6-11 months significantly decreases infant mortality, early neonatal sepsis, acute respiratory infections and diarrhoea [23-26]. In a prospective observational birth cohort study in Dhaka, Bangladesh, infants who received partial or no breastfeeding compared with infants who were exclusively breastfed in the first few months of life had a 2.2 fold higher risk of death in infancy and a 2.4 fold higher risk of acute respiratory infections [23]. An estimate of exclusive breastfeeding coverage in 2000 amongst the 40 countries with $90 \%$ of child deaths was only $39 \%$ [27]. Pneumonia incidence could be reduced by $15-23 \%$ with universal exclusive breastfeeding [28]. In addition universal coverage of exclusive breastfeeding could reduce child deaths by $13 \%$ [27]. This estimate took into account that exclusive breastfeeding in HIV infected mothers could result in the infant becoming infected. The estimated reduction in child 
deaths would have been $15 \%$ if this were not the case [27]. However, specific issues regarding breastfeeding in HIVinfected mothers must be considered, including the availability of an alternative safe milk supply, the potential for HIV transmission, the social and environmental circumstances and maternal preference.

\section{Optimizing Nutrition}

Stunting, underweight and micronutrient deficiency have been identified as risk factors for childhood pneumonia and for more severe pneumonia [3, 29, 30]. Malnutrition is associated with a poor outcome in children with pneumonia, consequently efforts to reduce poor nutrition are likely to reduce the burden and severity of pneumonia [29, 31]. However there is a lack of interventional research in this area. Jones et al. estimated a $6 \%$ reduction in child mortality with complimentary feeding in children $6-23$ months of life [27].

\section{Micronutrient Supplementation}

Zinc deficiency is common in low and middle income countries [32]. Zinc is important in skin and mucous membrane maintenance, leukocyte function and cytokine expression [33]. Supplemental zinc given either daily or as a weekly dose has been shown to decrease the incidence of pneumonia in young children in zinc deficient areas [34-36]. In a randomized controlled trial in Bangladesh children under 2 years given zinc $70 \mathrm{mg}$ once weekly for 12 months had a reduced pneumonia incidence [199/809 children receiving zinc versus $286 / 812$ children receiving placebo developed pneumonia (RR $0.83 ; 95 \% \mathrm{CI} 0.73$ to 0.95 )] [34]. This translates into a $17 \%$ reduction in pneumonia incidence and a $49 \%$ reduction in severe pneumonia in children receiving zinc supplementation. Zinc appears safe in HIV infected children [35]. Food supplementation with zinc has the potential to reduce pneumonia incidence by $14-25 \%$ (90\% CI 8-30) [28]. The role of zinc in the treatment of pneumonia is less clear. One controlled trial assessing the effect of zinc administered during a severe episode of pneumonia showed improvement in all severe pneumonia indicators and a shortened duration of hospital stay in zincsupplemented children. However other studies have not confirmed these findings or have reported worsening of acute hypoxia $[37,38]$. Results from ongoing trials in Nepal, Tanzania and Bangladesh are awaited.

Vitamin A significantly reduces the severity of measles associated pneumonia, reducing pneumonia associated morbidity and mortality by half (RR $0.51 ; 95 \% \mathrm{CI} 0.35$ to 0.74) [39]. However, Vitamin A supplementation has no impact on non-measles pneumonia incidence or pneumonia related mortality [29]. There is little evidence for the effect of supplementation with other micronutrients for preventing pneumonia in children.

\section{Indoor Air Pollution}

Indoor air pollution produced by the use of solid fuels such as wood, dung, crop waste and coal has been identified as a potentially modifiable risk factor for childhood pneumonia [40] Solid fuels are used by over 3 million people worldwide [28]. A recent meta-analysis of exposure to indoor air pollution showed an increased risk of pneumonia in young children exposed to unprocessed solid fuels (OR 1.78; 95\% CI 1.45 to 2.18), with a similarly increased risk of severe pneumonia [41]. Two interventions for reducing indoor air pollution have been investigated: switching to cleaner gaseous fuels (liquefied petroleum gas, kerosene or ethanol) in the household or improved combustion and ventilation through high-quality, well maintained biomass stoves. Using these interventions could reduce pneumonia incidence by $22-46 \%$ [28].

\section{Handwashing}

Handwashing with soap reduces the risk of acute respiratory infections and diarrhoea [42]. In a randomized controlled trial in Pakistan, neighbourhoods received handwashing education and then were randomly provided with plain or antibacterial soap. Control neighbourhoods received neither education nor soap. Children $<5$ years from the household who received soap had a $50 \%$ reduction in pneumonia episodes $(95 \% \mathrm{CI}-65$ to -34$)$ [42]. There was no difference between the households that used plain or antibacterial soap [42]. Widespread implementation of handwashing when used together with improved water and sanitation has been estimated to reduce child deaths by $3 \%$ [27].

\section{Immunisation}

Development of vaccines against the common respiratory pathogens has been a major advance in reducing the global burden of childhood pneumonia. Pertussis and measles immunisation, as part of the global Expanded Program on Immunisation (EPI), have significantly reduced childhood deaths in low and middle income countries [43, 44]. Conjugate vaccines against two of the common bacterial causes of childhood pneumonia, $H$. influenzae type $\mathrm{b}(\mathrm{Hib})$ and $S$. pneumoniae, are now available with widespread coverage in high income countries. However, these vaccines have not yet been widely incorporated into the EPI of most low and middle income countries.

Measles vaccine is part of the EPI schedule. Widespread coverage of the measles vaccine has been highly effective for reducing measles associated pneumonia and deaths, averting 11 million measles deaths from 2000-2007, representing a decrease of $74 \%$ in measles associated mortality [43]. A recent review of vaccine coverage in 45 low and middle income countries estimates measles vaccine coverage to be $74 \%$ (IQR 58-83). However, only $54 \%$ of children had received their initial measles vaccine by 12 months of age [45]. With improved vaccine coverage to above $90 \%$, a decrease in under 5 mortality by around $1 \%$ could be achieved [27],

Pertussis vaccine had been part of the EPI since 1974. In 2003 pertussis vaccination prevented over 38 million cases of pertussis and 607000 pertussis related deaths [44]. However, in the same year there were still an estimated 279 000 deaths related to pertussis pneumonia, $90 \%$ of which occurred in low income countries. The greatest burden of pertussis related mortality is in the first 6 months of life. The recommended pertussis vaccine schedule is three doses at 6 , 10 and 14 weeks. Recent estimates of pertussis vaccine coverage in low and middle income countries are $84 \%$ coverage of $1^{\text {st }}$ dose and $63 \%$ coverage of the $3^{\text {rd }}$ dose [45]. However, dose timing was markedly delayed with only $57 \%$ of $1^{\text {st }}$ doses given by 12 weeks and only $27 \%$ of $3^{\text {rd }}$ doses 
given by 5 months [45]. Improvement in vaccine timing and higher vaccine coverage may reduce the burden of mortality due to pertussis in low and middle income countries.

The $\boldsymbol{H}$. influenzae type b (Hib) conjugate vaccine has been available for almost 20 years and is highly effective in both high and low income settings [46-53]. Hib reduces the incidence of bacteraemic pneumonia by more than $80 \%$ and radiologically confirmed pneumonia by $22-55 \%$ in immunocompetent children [46, 47, 54]. In addition the vaccine reduces asymptomatic nasopharyngeal carriage protecting unvaccinated people through development of herd immunity [55-57]. The Hib vaccine has reduced protection against invasive disease in HIV infected children not on antiretroviral therapy, but protects against the development of pneumonia or severe disease in a substantial proportion due to the increased susceptibility of immunocompromised children to such illness [58]. Hib vaccine is a cost effective intervention to reduce childhood pneumonia and mortality [59]. 61 of 72 GAVI-eligible countries have already included Hib into their routine immunization schedule in 2009 [22]. However, improved vaccine coverage in high burden countries not yet using Hib could reduce global pneumonia mortality by a further $22-34 \%$ [28].

The pneumococcal conjugate vaccine (PCV) has large potential to reduce the burden of childhood pneumonia and mortality. S. pneumoniae is consistently reported to be the commonest aetiological agent in childhood pneumonia in low and middle income countries accounting for 13.8 million cases of pneumonia a year globally, $94 \%$ in low and middle income countries [11]. In addition the HIV epidemic has considerably increased the burden and severity of pneumococcal pneumonia $[60,61]$. PCV7 is a highly effective vaccine, reducing the incidence of bacteraemic pneumonia, radiologically confirmed pneumonia (by 13$37 \%$ ) and clinical pneumonia $[62,63]$. However the sensitivity of chest radiographs in detecting pneumococcal pneumonia is low and hence the burden of pneumonia prevented is likely to be much higher. A reduction in all cause pneumonia of $61 \%$ was reported in a North American study [64]. As many of the vaccine serotypes associated with antimicrobial resistance are included in the vaccine, PCV has also reduced antibiotic resistant disease [62, 65]. In a rural setting in the Gambia, PCV9 reduced childhood mortality by $16 \%$, translating into 7 deaths prevented per 1000 children immunized [63]. PCV7 is immunogenic in HIV infected children [66, 67]. Although there is decreased efficacy in HIV-infected compared to uninfected children, the overall burden prevented is much higher in HIV infected children due to their susceptibility to severe disease [68]. Concern about replacement disease with non-vaccine serotypes due to an increase in non-vaccine serotype disease in communities with wide vaccine coverage has been raised [69-71]. However, a sustained and substantial reduction in invasive pneumococcal disease has occurred overall in populations with widespread use of PCV7. Cost effectiveness analysis shows that PCV is cost effective in low and middle income countries, especially due to the development of herd immunity [72]. Comprehensive PCV coverage could reduce childhood pneumonia mortality by $23-35 \%$ [28].

\section{Antibiotic Prophylaxis}

\section{Pneumocystis jirovecii Pneumonia (PCP) Prophylaxis}

Prophylaxis against PCP with oral trimethoprimsulphamethoxazole (TMP-SMX), is effective to prevent primary and secondary infection with PCP in HIV-infected children. This requires timely identification of HIV infected mothers and children, and infrastructure and resources for implementation [73]. In countries where routine prophylaxis has been instituted, a dramatic reduction in PCP has occurred. In the only randomized controlled trial of PCP prophylaxis in HIV-infected children, a Zambian study found a $43 \%$ reduction in mortality and a $23 \%$ reduction in hospitalizations in children taking prophylaxis [74]. As PCP has been reported in HIV-exposed uninfected children, TMP-SMX prophylaxis may be considered in these infants, until 6 months of age. Current WHO guidelines recommend use of TMP-SMX prophylaxis in HIV-exposed and HIVinfected children from 4-6 weeks of age [75]. Prophylaxis may be discontinued if the child's HIV status is confirmed to be negative and breast feeding has ceased for at least 6 weeks or in HIV-infected children older than 18 months when there is sustained immune reconstitution on HAART. The recommended dose of TMP-SMX is $5 \mathrm{mg} / \mathrm{kg}$ of TMP component (maximum dose $80 \mathrm{mg}$ TMP), given daily. If TMP-SMX is not tolerated alternatives include dapsone $2 \mathrm{mg} / \mathrm{kg}$ once daily, parenteral pentamidine $4 \mathrm{mg} / \mathrm{kg}$ every 2 to 4 weeks or aerosolized pentamidine, 300mg via Respigard II inhaler if the child is older than 5 years of age [76].

\section{Prevention of Mycobacterial Disease}

Isoniazid (INH) has been used successfully as preventive therapy in HIV uninfected children at risk of TB disease [77]. All children under 5 years exposed to a household TB contact should receive INH prophylaxis $(10 \mathrm{mg} / \mathrm{kg})$ daily for six months to prevent primary infection. HIV-infected children exposed to a household contact should receive prophylaxis irrespective of age.

In HIV-infected adults with a positive tuberculin skin test, prophylaxis reduces the risk of TB disease by $36 \%$ [78]. A randomized control trial of INH prophylaxis versus placebo conducted in South African HIV-infected children not on HAART living in an area of high TB prevalence showed a significant reduction in TB incidence and mortality. INH reduced the incidence of TB by $72 \%$ and mortality by $54 \%$ [79]. Thus INH may be an effective public health intervention for HIV-infected children living in high TB prevalence areas. However further study of the long term protective efficacy, the optimal duration of prophylaxis, and the efficacy in HIV-infected children on HAART is needed. Potential concerns with using INH prophylaxis are the need to exclude TB disease in children before initiating this and the impact on mycobacterial drug sensitivity [80]. Long term INH prophylaxis appears to be safe in HIV-infected children $[79,81]$.

\section{Highly Active Antiretroviral Therapy (HAART)}

The use of HAART has decreased the incidence and severity of HIV associated pneumonia, and mortality, especially when initiated early in life. Comparative incident 
ratios of opportunistic infections in HIV-infected children in the HAART era and pre-HAART era have reported a more than 5 fold reduction in the incidence of bacterial pneumonia and respiratory opportunistic infections [82, 83]. A recent South African study showed a $76 \%$ reduction in all cause mortality in infants less than 12 weeks who were randomized to receive HAART at HIV diagnosis irrespective of CD4 count or clinical staging compared to the use of deferred HAART (when CD4 counts fell below $20 \%$ or $25 \%$ or clinical criteria were met). Although the cause of death was unknown in many children, infections were the commonest cause of death in those dying in hospital [84]. The WHO has revised their recommendations to recommend early initiation of HAART in infants as soon as they are confirmed to be HIV-infected [85].

\section{MANAGEMENT OF CHILDHOOD PNEUMONIA IN LOW AND MIDDLE INCOME COUNTRIES}

\section{Case Management of Childhood Pneumonia}

The WHO developed case management guidelines for childhood pneumonia based on the premise that most fatal pneumonia was caused by bacterial infections, that these could be treated effectively with antibiotics, that children could access health care facilities and that a combination of clinical signs that could be taught to health care workers would identify most pneumonia cases. These were later incorporated into the IMCI guidelines. The guidelines aim to ensure prompt recognition and appropriate treatment of pneumonia in an accessible community based setting and to identify children at risk or with severe pneumonia who should be referred to health care facilities (Table 2). The guidelines use cough or difficulty in breathing as the entry criteria; increased respiratory rate above age norm or lower chest wall indrawing are used to diagnose pneumonia or severe pneumonia. Additional signs such as decreased feeding, lethargy, convulsions or persistent vomiting are used to diagnose very severe pneumonia. This algorithm can be successfully taught and used by community health workers [86-88].

Although these guidelines are sensitive for identifying children with pneumonia, they lack specificity. This may be particularly problematic in children presenting with wheezing [89] who may have asthma or viral bronchiolitis and in children with malaria who may present with tachypnoea [90]. In addition clinical management of children living in areas with high HIV and TB prevalence or with high rates of malnutrition is more complicated, requiring adaptation of management guidelines. The clinical overlap of co-morbid diseases must be considered in local case management strategies.

Case management has been shown to be effective in decreasing pneumonia related child mortality [86]. A metaanalysis estimating the impact of case management indicated a reduction of $24 \%$ in total child mortality and $36 \%$ reduction in pneumonia related mortality in children under 5 years [86]. However challenges still exist in implementing effective case management. Only half of the countries with the highest pneumonia mortality surveyed in a recent review reported implementing community based case management [91]. Of these many reported very limited scale of implementation, covering less than $10 \%$ of the child population [91]. Delayed care seeking is an important risk for fatal childhood pneumonia and is commonly reported [92]. In 2004 only $29 \%$ of Ugandan children with symptoms of pneumonia reported to have used first or second line antibiotics during their illness [90]. In a recent review of care seeking in children with fatal pneumonia, carers waited a median of 2 days from recognition of illness before seeking care outside of home. Most care givers (57\%) had used selfprescribed antibiotics before consulting health providers, leading to delayed care seeking [93]. Insufficient dosing with low quality drugs is common in low income countries [90] and a challenge that needs to be addressed.

A further challenge is improving case management at the health facility of first contact. Poor quality care in district hospitals has been reported to be problematic [94, 95]. Using facility based case management guidelines correctly and assuming access to resources such as antibiotics and oxygen has the potential to reduce children pneumonia mortality by 29-45\% [28]. Most pneumonia deaths occur in children with severe pneumonia $[17,96]$, hence identifying and appropriately managing children with severe pneumonia is critical and may lead to timely use of alternative effective treatments when indicated.

National implementation of such guidelines can be effectively done, as has been recently described in Malawi, which resulted in a more than $50 \%$ reduction in paediatric pneumonia deaths [97].

\section{MANAGEMENT OF PNEUMONIA IN THE COMMUNITY}

The WHO has recently updated the guidelines for management of pneumonia (Table 3) [85]. Pneumonia, defined as rapid breathing should be treated with oral

Table 2. WHO and IMCI Guidelines for Assessment of Severity of Pneumonia in Children [16, 133]

\begin{tabular}{|c|c|c|c|}
\hline WHO Classification & IMCI Classification & Clinical Signs & Management \\
\hline No pneumonia & Cough or cold & No signs of pneumonia or very severe disease & $\begin{array}{l}\text { Symptomatic treatment, advise carer when to return } \\
\text { immediately, follow up in } 5 \text { days if not improving }\end{array}$ \\
\hline Non-severe pneumonia & Pneumonia & Fast breathing $^{*}$ & $\begin{array}{l}\text { Give oral antibiotics for } 3 \text { days, advise the carer } \\
\text { when to return immediately, follow up in } 2 \text { days }\end{array}$ \\
\hline Severe pneumonia & \multirow{2}{*}{$\begin{array}{l}\text { Severe pneumonia or } \\
\text { very severe disease }\end{array}$} & Chest indrawing & $\begin{array}{l}\text { Give first dose of antibiotic } \\
\text { Refer urgently to hospital }\end{array}$ \\
\hline Very severe disease & & Any general danger sign ${ }^{\#}$ & $\begin{array}{l}\text { Give first dose of antibiotic } \\
\text { Refer urgently to hospital }\end{array}$ \\
\hline
\end{tabular}

${ }^{*}<2$ months, 60 breaths per min, child 2-12 months: $>50$ breaths per minute; Child 12-59 months: $>40$ breaths per minute

${ }^{\#}$ Lethargy, inability to feed, convulsions, vomiting everything. 
Table 3. Current Antibiotic Guidelines Based on Updated WHO and IMCI Recommendations for Community Acquired Pneumonia in Children [98]

\begin{tabular}{|c|c|c|c|c|c|}
\hline & Drug & Route & Dose & Frequency & Duration \\
\hline Pneumonia & $\begin{array}{c}\text { Amoxicillin } \\
\text { Or } \\
\text { Trimethoprim-sulphamethoxazole** }\end{array}$ & $\begin{array}{l}\text { Oral } \\
\text { Oral }\end{array}$ & $\begin{array}{l}15 \mathrm{mg} / \mathrm{kg} \\
\text { or } 30 \mathrm{mg} / \mathrm{kg} \\
4 \mathrm{mg} / \mathrm{kg} \text { trimethoprim component }\end{array}$ & $\begin{array}{l}3 \text { times daily } \\
2 \text { daily } \\
2 \text { daily }\end{array}$ & $\begin{array}{l}5 \text { days } \\
3 \text { days } \\
3 \text { or } 5 \text { days }\end{array}$ \\
\hline $\begin{array}{l}\text { Severe } \\
\text { pneumonia }\end{array}$ & $\begin{array}{l}\text { Beta lactam antibiotic: } \\
\text { Benzyl penicillin } \\
\text { Ampicillin }\end{array}$ & Intravenous & $\begin{array}{l}50 \text { 000units } / \mathrm{kg} \\
25 \mathrm{mg} / \mathrm{kg}\end{array}$ & $\begin{array}{l}4 \text { times daily } \\
3 \text { times daily }\end{array}$ & $\begin{array}{l}\text { Until child improves } \\
\text { then change to oral } \\
\text { amoxicillin, total } 5 \text { days }\end{array}$ \\
\hline $\begin{array}{l}\text { Very severe } \\
\text { pneumonia }\end{array}$ & $\begin{array}{c}\text { Beta lactam antibiotic: } \\
\text { Benzyl penicillin or Ampicillin } \\
\text { AND } \\
\text { Gentamicin }\end{array}$ & $\begin{array}{r}\text { Intravenous } \\
\text { Intravenous } \\
\text { Intravenous }\end{array}$ & $\begin{array}{l}50000 \mathrm{units} / \mathrm{kg} \\
50 \mathrm{mg} / \mathrm{kg} \\
7.5 \mathrm{mg} / \mathrm{kg}\end{array}$ & $\begin{array}{l}4 \text { times daily } \\
3 \text { times daily } \\
1 \text { daily }\end{array}$ & $\begin{array}{l}10 \text { days }^{\#} \\
10 \text { days }^{\#} \\
10 \text { days }^{\#}\end{array}$ \\
\hline
\end{tabular}

**Not recommended in a child on TMP-SMX prophylaxis.

"Until child improves, then continue oral antibiotic 3 times daily to complete 10 days.

antibiotics. Previous WHO recommendations of amoxicillin $(15 \mathrm{mg} / \mathrm{kg})$ three times a day or trimethoprim-sulphamethoxazole (TMP-SMX) (4mg/kg TMP component) have recently been updated [98]. Amoxicillin $30 \mathrm{mg} / \mathrm{kg}$ may be given twice a day. A recent study comparing the pharmacokinetics of $15 \mathrm{mg} / \mathrm{kg}$ amoxicillin given three times a day with $25 \mathrm{mg} / \mathrm{kg}$ amoxicillin given twice a day to children aged 2-59 months, found the two regimens comparable [99], suggesting that the twice daily regimen is as effective and may result in better adherence. There is no established link between resistance to co-trimoxazole and response to non-severe pneumonia treatment [100, 101]. A large randomized controlled trial in Pakistan, that compared the clinical efficacy of twice daily oral amoxicillin with twice daily TMP-SMX found them to be equally effective for pneumonia [101]. A second study of children with severe pneumonia, comparing amoxicillin with co-trimoxazole showed amoxicillin to be more effective than cotrimoxazole [102]. However, because of the high rate of background antibiotic resistance, amoxicillin should preferably be used as first line treatment for non-severe pneumonia in HIV infected children.

Recent studies have shown shorter course (3 day) antibiotic therapy for immunocompetent children with pneumonia to be as effective as a 5 day course [103]. Two large randomized trials found 3 days of amoxicillin to be equivalent to 5 days $[103,104]$. The first study randomized 2000 children in outpatient departments in seven hospitals in Pakistan to either 3 or 5 days of amoxicillin $15 \mathrm{mg} / \mathrm{kg}$ every 8 hours. Rates of treatment failure at five days were similar in the 2 groups [209 (21\%) vs 202 (20\%), (95\% CI -1.8 to 3.2)]. The disease relapse rates were also similar in the groups [12 (1\%) vs 13(1\%) (95\% CI-0.6 to 0.8)] [103]. The second study randomized 2188 children from 7 outpatient sites in India to either 3 or 5 -days of amoxicillin at $30-50 \mathrm{mg} / \mathrm{kg} / \mathrm{day}$. Clinical cure was achieved in $980(89.5 \%)$ in the 3-day group and $983(89.9 \%)$ in the 5 day group (95\% CI -2.1 to $3.0)$. Rates of relapse were also similar in both groups $[5.3 \%$ vs $4.4 \%$ (95\% CI -1.0 to 3.0)] [104]. Shorter course therapy has the advantages of being more cost effective, improved adherence and less development of antimicrobial resistance. However, these results are not generalisable to high HIV prevalence areas.
In addition, with the increased use of $\mathrm{Hib}$ and pneumococcal conjugate vaccines, other bacteria such as $\mathrm{S}$ aureus and viruses will become increasingly important in the aetiology of childhood pneumonia [105]. Future research to monitor and accurately diagnose the aetiology of childhood pneumonia is needed.

Children with no pneumonia (normal respiratory rate and no chest indrawing) often have an upper respiratory tract infection and should be treated symptomatically.

\section{MANAGEMENT OF PNEUMONIA AT HEALTH FACILITY}

The WHO classification of pneumonia severity into severe and very severe categories has debatable clinical relevance and has been recently reviewed elsewhere [106]. Moreover many health workers do not make this differentiation clinically and treat all children with WHO classified severe and very severe pneumonia according to guidelines for very severe pneumonia [94]. For the purpose of this review the management of severe and very severe pneumonia has been combined into management of severe pneumonia requiring hospitalization.

The clinical signs used in the case management guidelines have high sensitivity to identify severe disease but not to detect hypoxia requiring oxygen therapy [107-110]. Hypoxemia in children with severe pneumonia is common; a recent meta analysis reported that $13 \%$ of children admitted to hospital with severe pneumonia had hypoxemia [111]. This analysis did not include many children who do not present at a health facility and hence underestimates the true burden of hypoxemic pneumonia. Hypoxemia is associated with more severe disease and is a risk factor for death [111, 112]. Clinically signs such as cyanosis, respiratory rate $>60$ breaths per minute, nasal flaring, inability to drink, head nodding, chest wall indrawing and altered mental state are not sensitive measures of hypoxia [113-117]. Up to $20 \%$ of children with WHO severe pneumonia (without clinical signs of hypoxia such as cyanosis or drowsiness), were found to be hypoxic [111]. Pulse oximetry is the most reliable method for identifying hypoxia in children. Where pulse oximetry is not available respiratory rate $>60$ breath per minute and altered mental state are the most reliable 
clinical indicators [118]. Routine screening of hypoxia with pulse oximetry and improved oxygen delivery systems have been shown to have a significant reduction in mortality [119121]. Improved oxygen delivery systems in 5 hospitals in Papua New Guinea reduced the risk of death for a child with pneumonia by $35 \%$ (risk ratio $0.65 ; 95 \%$ CI $0.52-0.78$ ) [119]. Identifying hypoxemia accurately has the potential to improve treatment and outcome in childhood pneumonia in low income countries by improving identification of severe disease and guiding treatment and monitoring.

Children with severe pneumonia and hypoxia or general danger signs (lethargy, decreased feeding) should be treated with intravenous or intramuscular antibiotics and oxygen and referred to hospital. Until recently WHO guidelines recommended a combination of benzyl penicillin and gentamicin or chloramphenicol [122, 123]. However, a recently published randomized controlled trial conducted in seven middle and low income countries in Asia, Africa and South America compared the clinical efficacy of intravenous ampicillin $(50 \mathrm{mg} / \mathrm{kg}$ four times a day) and gentamicin $(7.5$ $\mathrm{mg} / \mathrm{kg}$ once a day) with chloramphenicol $(25 \mathrm{mg} / \mathrm{kg}$ three times a day) [124]. There was a higher treatment failure rate in the chloramphenicol group at 5 days $(16 \%$ versus $11 \%$; relative risk $1.43 ; 95 \%$ CI $1.03-1.97$ ), at 10 days (19\% versus $14 \%$; relative risk 1.37 ; $95 \%$ CI $1.03-1.83$ ) and 21 days (22\% versus $16 \%$; relative risk 1.34 ; 95\% CI 1.02-1.75). Bacteremia was associated with a higher treatment failure rate in the chloramphenicol group [124]. Consequently hospitalised children with severe pneumonia should initially be treated with a B-lactam antibiotic and gentamicin. An alternative would be a second or third generation cephalosporin used alone especially if allergy or toxicity precludes use of the former combination.

Beta-lactam antibiotics have excellent penetration into respiratory secretions. No correlation between antibiotic resistance and treatment failure has been shown [125]. A recent study investigating the effect of in vitro beta-lactam resistant pneumococci on clinical outcome in children with severe pneumonia, showed excellent response to treatment with either Penicillin G (200 000units/kg/day) intravenously or ampicillin $(150 \mathrm{mg} / \mathrm{kg} /$ day) intravenously even in the presence of penicillin resistant pneumococci [125]. Antibiotic choice should be modified according to the culture results and antimicrobial sensitivities once available.

Admission to hospital and use of intravenous antibiotics has resource implications, requires intravenous access and may be a risk for nosocomial infection. Recent evidence suggests that oral amoxicillin is equally as efficacious as intravenous antibiotics in children admitted to hospital with severe pneumonia [126, 127]. A multicentre study in eight low and middle income countries in Africa, Asia and South America compared the efficacy of oral versus intravenous antibiotics in children admitted to hospital with severe pneumonia [126]. Children aged 3-59 months were randomized to receive either oral amoxicillin $(15 \mathrm{mg} / \mathrm{kg} / \mathrm{dose}$ three times a day) or intravenous penicillin (50 000IU $/ \mathrm{kg}$ four times a day) for 48 hours, after which, if symptoms improved, they were discharged home with a 5 day course of oral therapy amoxicillin. Treatment failure at 48 hours in each group was similar $[19 \%$ in the amoxicillin group vs $19 \%$ in the penicillin group (95\% CI -4.2 to 3.3)] [126]. In another recent study at seven sites in Pakistan in children 3-59 months with severe pneumonia, five days of high dose amoxicillin $(80-90 \mathrm{mg} / \mathrm{kg}$ per day) given as outpatient therapy was compared with intravenous ampicillin $(25 \mathrm{mg} / \mathrm{kg}$ four times a day) for 48 hours followed by three days oral amoxicillin (80-90mg/kg per day in two doses). The number of children who failed treatment in the 2 groups was similar $[7.5 \%$ in ambulatory vs $8.6 \%$ in the hospital group at day $6(95 \%$ CI -1.3 to 3.5$)$ ] [127]. However these results are not applicable in areas with high HIV prevalence. In addition extrapolation of these results to areas of high pneumonia associated mortality may not be possible as the mortality rate was only $0.2 \%$, which is lower than that in many other studies [127]. The use of pulse oximetry to identify children with hypoxia may however be an excellent tool to screen children for outpatient treatment.

Failure to respond adequately to antibiotic treatment is a challenge in childhood pneumonia. Treatment failure rates have been reported to range from 9 to $21 \%[17,102,103$, $126,128]$. Identifying children with severe pneumonia who are likely to fail treatment may lead to timely switch to alternative effective treatment and hence decrease mortality. Recent research has included identifying risk factors for treatment failure in children with pneumonia in low and middle income countries [17] and developing clinical tools that could be used in resource limited settings to improve management of at risk children. $\mathrm{Fu}$ et al. recently showed that using clinical signs at presentation and after 24 hours could be used to predict clinical failure of oral amoxicillin therapy [129]. Using oxygen saturations had equal predictive value at $12 \mathrm{hrs}$ [129]. Young age, increased initial respiratory rate and baseline hypoxia were all associated with increased risk of treatment failure [129]. In another study, lack of exclusive breastfeeding, overcrowding and chest radiographic signs of pneumonia were related to failure of first line therapy [130]. Others have also documented association between chest radiographic pathology and disease severity [131]. Mamtani et al. developed a clinical tool using simple clinical parameters to predict risk of treatment failure: age of child, excess age-specific respiratory rate at baseline and at $24 \mathrm{hr}$ of hospitalization, with a $66-70 \%$ predictive accuracy for treatment failure [132]. It is possible that monitoring of simple clinical signs at presentation and after 12 hours together with routine monitoring of oxygen saturation with pulse oximetry could reliably identify those children that require hospitalization and consideration of alternative therapy.

\section{RESEARCH PRIORITIES}

More research on childhood pneumonia is needed to better understand the burden and to develop more effective and cost effective preventative and treatment strategies. Specific areas of importance include:

- Development of better tools for pneumonia diagnosis

- Development of rapid, reliable methods for aetiological diagnosis

- Study of the changing burden of disease in the post Hib, post PCV era

- Assessment of the efficacy of preventative strategies in HIV-infected children with limited access to HAART and in the era of HAART 
- Improved preventative strategies including development of new and combination vaccines

- Improved treatment strategies including shorter course therapy and oral therapy in HIV-infected and uninfected children

- Monitoring of the development of antimicrobial resistance and impact on treatment interventions

- Cost efficacy analysis of specific preventative and therapeutic interventions

\section{SUMMARY}

Childhood pneumonia continues to be the major cause of mortality in low and middle income countries. Implementation of preventive strategies must be intensified, particularly immunisation with Hib and PCV. For treatment, case management strategy must be more widely implemented at the community level, with attention to operational and educational aspects. Better access to oxygen delivery systems is needed. Treatment and preventative strategies require adaptation in high HIV prevalence areas to include interventions that are specific for HIV-infected children. Further research to develop better diagnostic tests, preventative and treatment strategies is needed, especially when high coverage with Hib and PCV has been achieved.

\section{REFERENCES}

[1] Black RE, Cousens S, Johnson HL, et al. Global, regional and national causes of child mortality in 2008: a systematic analysis. Lancet 2010; 375: 1969-87.

[2] Rudan I, Tomaskovic L, Boschi-Pinto C, Campbell H. Global estimate of the incidence of clinical pneumonia among children under five years of age. Bull World Health Organ 2004; 82(12): 895-903.

[3] Rudan I, Boschi-Pinto C, Biloglav Z, Mulholland K, Campbell H. Epidemiology and etiology of childhood pneumonia. Bull World Health Organ 2008; 86(5): 408-16.

[4] Puchalski Ritchie LM, Howie SR, Arenovich T, et al. Long-term morbidity from severe pneumonia in early childhood in The Gambia, West Africa: a follow-up study. Int J Tuberc Lung Dis 2009; 13(4): 527-32

[5] Mok JY, Simpson H. Outcome for acute bronchitis, bronchiolitis, and pneumonia in infancy. Arch Dis Child 1984; 59(4): 306-9.

[6] Wesley AG. Prolonged after-effects of pneumonia in children. S Afr Med J 1991; 79(2): 73-6.

[7] Shann F. Etiology of severe pneumonia in children in developing countries. Pediatr Infect Dis J 1986; 5: 247-51.

[8] Forgie IM, O'Neill KP, Lloyd-Evans N, et al. Etiology of acute lower respiratory tract infections in Gambian children. II. Acute lower respiratory tract infection in children ages one to nine years presenting at the hospital. Pediatr Infect Dis J 1991; 10(1): 42-7.

[9] Forgie IM, O'Neill KP, Lloyd-Evans N, et al. Etiology of acute lower respiratory tract infections in Gambian children. I. Acute lower respiratory tract infections in infants presenting at the hospital. Pediatr Infect Dis J 1991; 10(1): 33-41.

[10] Falade AG, Mulholland EK, Adegbola RA, Greenwood BM. Bacterial isolates from blood and lung aspirate cultures in Gambian children with lobar pneumonia. Ann Trop Paediatr 1997; 17(4): 315-9.

[11] O'Brien KL, Wolfson LJ, Watt JP, et al. Burden of disease caused by Streptococcus pneumoniae in children younger than 5 years. global estimates. Lancet 2009; 374(9693): 893-902.

[12] Watt JP, Wolfson LJ, O'Brien KL, et al. Burden of disease caused by Haemophilus influenzae type $\mathrm{b}$ in children younger than 5 years. global estimates. Lancet 2009; 374(9693): 903-11.

[13] Berkley JA, Lowe BS, Mwangi I, et al. Bacteremia among children admitted to a rural hospital in Kenya. N Engl J Med 2005; 352(1): $39-47$.

[14] Graham SM, English M. Non-typhoidal salmonellae. A management challenge for children with community-acquired invasive disease in tropical African countries. Lancet 2009; 373(9659): 267-9.

[15] O'Dempsey TJ, McArdle TF, Lloyd-Evans N, et al. Importance of enteric bacteria as a cause of pneumonia, meningitis and septicemia among children in a rural community in The Gambia, West Africa. Pediatr Infect Dis J 1994; 13(2): 122-8.

[16] WHO. Integrated management of childhood illness chart booklet. 2005

[17] McNally LM, Jeena PM, Gajee K, et al. Effect of age, polymicrobial disease, and maternal HIV status on treatmen response and cause of severe pneumonia in South African children. a prospective descriptive study. Lancet 2007; 369: 1440-51.

[18] AIDS epidemic update. 2008 [http://www.unaids.org/en/Knowl edgeCentre/HIVData/GlobalReport/2008/].

[19] Jeena P, Thea DM, MacLeod WB, et al. Failure of standard antimicrobial therapy in children aged 3-59 months with mild or asymptomatic HIV infection and severe pneumonia. Bull World Health Organ 2006; 84(4): 269-75.

[20] Zar HJ, Hanslo D, Tannenbaum E, et al. Aetiology and outcome of pneumonia in human immunodeficiency virus-infected children hospitalized in South Africa. Acta Paediatr 2001; 90(2): 119-25.

[21] Madhi SA, Petersen K, Madhi A, Khoosal M, Klugman KP. Increased disease burden and antibiotic resistance of bacteria causing severe community-acquired lower respiratory tract infections in human immunodeficiency virus type 1-infected children. Clin Infect Dis 2000; 31(1): 170-6.

[22] WHO/UNICEF. Global Action Plan for Prevention and Control of Pneumonia (GAPP). World Health Organization/The United Nations Children's Fund; 2009.

[23] Arifeen S, Black RE, Antelman G, Baqui A, Caulfield L, Becker S. Exclusive breastfeeding reduces acute respiratory infection and diarrhea deaths among infants in Dhaka slums. Pediatrics 2001; 108(4): E67.

[24] Ashraf RN, Jalil F, Zaman S, et al. Breast feeding and protection against neonatal sepsis in a high risk population. Arch Dis Child 1991; 66(4): 488-90.

[25] Wright AL, Bauer M, Naylor A, Sutcliffe E, Clark L. Increasing breastfeeding rates to reduce infant illness at the community level. Pediatrics 1998; 101(5): 837-44

[26] WHO. Optimal duration of exclusive breastfeeding. Report of an expert consultation. Geneva, Switzerland: WHO 2001.

[27] Jones G, Steketee RW, Black RE, Bhutta ZA, Morris SS. How many child deaths can we prevent this year? Lancet 2003; 362(9377): 65-71.

[28] Niessen LW, ten Hove A, Hilderink H, Weber M, Mulholland K, Ezzati M. Comparative impact assessment of child pneumonia interventions. Bull World Health Organ 2009; 87(6): 472-80.

[29] Roth DE, Caulfield LE, Ezzati M, Black RE. Acute lower respiratory infections in childhood. opportunities for reducing the global burden through nutritional interventions. Bull World Health Organ 2008; 86(5): 356-64.

[30] Gakidou E, Oza S, Vidal Fuertes C, et al. Improving child survival through environmental and nutritional interventions. the importance of targeting interventions toward the poor. JAMA 2007; 298(16): 1876-87.

[31] Black RE, Allen LH, Bhutta ZA, et al. Maternal and child undernutrition. global and regional exposures and health consequences. Lancet 2008; 371(9608): 243-60.

[32] Wuehler SE, Peerson JM, Brown KH. Use of national food balance data to estimate the adequacy of zinc in national food supplies. methodology and regional estimates. Public Health Nutr 2005; 8(7): 812-9.

[33] Shankar AH, Prasad AS. Zinc and immune function. the biological basis of altered resistance to infection. Am J Clin Nutr 1998; 68(2 Suppl): 447S-63S.

[34] Brooks WA, Santosham M, Naheed A, et al. Effect of weekly zinc supplements on incidence of pneumonia and diarrhoea in children younger than 2 years in an urban, low-income population in Bangladesh. randomised controlled trial. Lancet 2005; 366(9490): 999-1004.

[35] Bobat R, Coovadia H, Stephen C, et al. Safety and efficacy of zinc supplementation for children with HIV-1 infection in South Africa a randomised double-blind placebo-controlled trial. Lancet 2005 366(9500): 1862-7.

[36] Bhandari N, Bahl R, Taneja S, et al. Effect of routine zinc supplementation on pneumonia in children aged 6 months to 3 
years. randomised controlled trial in an urban slum. BMJ 2002; 324(7350): 1358 .

[37] Bose A, Coles CL, Gunavathi, et al. Efficacy of zinc in the treatment of severe pneumonia in hospitalized children $<2 \mathrm{y}$ old. Am J Clin Nutr 2006; 83(5): 1089-96; quiz 1207.

[38] Mahalanabis D, Lahiri M, Paul D, et al. Randomized, double-blind, placebo-controlled clinical trial of the efficacy of treatment with zinc or vitamin A in infants and young children with severe acute lower respiratory infection. Am J Clin Nutr 2004; 79(3): 430-6.

[39] Hussey GD, Klein M. A randomized, controlled trial of vitamin A in children with severe measles. N Engl J Med 1990; 323(3): 160-

[40] Kirkwood BR, Gove S, Rogers S, Lob-Levyt J, Arthur P, Campbell H. Potential interventions for the prevention of childhood pneumonia in developing countries. a systematic review. Bull World Health Organ 1995; 73(6): 793-8.

[41] Dherani M, Pope D, Mascarenhas M, Smith KR, Weber M, Bruce N. Indoor air pollution from unprocessed solid fuel use and pneumonia risk in children aged under five years. a systematic review and meta-analysis. Bull World Health Organ 2008; 86(5): 390-8C.

[42] Luby SP, Halder AK. Associations among handwashing indicators, wealth, and symptoms of childhood respiratory illness in urban Bangladesh. Trop Med Int Health 2008; 13(6): 835-44.

[43] WHO. Progress in global measles control and mortality reduction, 2000-2007. Weekly Epidemiological Record (WER) 2008; 83(49): 441-8.

[44] WHO. Pertussis vaccines WHO position paper. Weekly Epidemiological Record 2005; 80(4): 31-9.

[45] Clark A, Sanderson C. Timing of children's vaccinations in 45 lowincome and middle-income countries. an analysis of survey data. Lancet 2009; 373(9674): 1543-9.

[46] De la Hoz F, Higuera AB, Di Fabio JL, et al. Effectiveness of Haemophilus influenzae type $b$ vaccination against bacterial pneumonia in Colombia. Vaccine 2004; 23(1): 36-42.

[47] Mulholland K, Hilton S, Adegbola R, et al. Randomised trial of Haemophilus influenzae type-b tetanus protein conjugate vaccine [corrected] for prevention of pneumonia and meningitis in Gambian infants. Lancet 1997; 349(9060): 1191-7.

[48] Adegbola RA, Secka O, Lahai G, et al. Elimination of Haemophilus influenzae type b (Hib) disease from The Gambia after the introduction of routine immunisation with a Hib conjugate vaccine. a prospective study. Lancet $2005 ; 366(9480)$ : 144-50.

[49] Adegbola RA, Usen SO, Weber M, et al. Haemophilus influenzae type $\mathrm{b}$ meningitis in The Gambia after introduction of a conjugate vaccine. Lancet 1999; 354(9184): 1091-2.

[50] Murphy TV, White KE, Pastor P, et al. Declining incidence of Haemophilus influenzae type $b$ disease since introduction of vaccination. JAMA 1993; 269(2): 246-8.

[51] Dagan R, Fraser D, Roitman M, et al. Effectiveness of a nationwide infant immunization program against Haemophilus influenzae b. The Israeli Pediatric Bacteremia and Meningitis Group. Vaccine 1999; 17(2): 134-41.

[52] Cowgill KD, Ndiritu M, Nyiro J, et al. Effectiveness of Haemophilus influenzae type $\mathrm{b}$ Conjugate vaccine introduction into routine childhood immunization in Kenya. JAMA 2006; 296(6): 671-8.

[53] Lewis RF, Kisakye A, Gessner BD, et al. Action for child survival. elimination of Haemophilus influenzae type $b$ meningitis in Uganda. Bull World Health Organ 2008; 86(4): 292-301.

[54] Baqui AH, El Arifeen S, Saha SK, et al. Effectiveness of Haemophilus influenzae type B conjugate vaccine on prevention of pneumonia and meningitis in Bangladeshi children. a case-control study. Pediatr Infect Dis J 2007; 26(7): 565-71.

[55] Adegbola RA, Mulholland EK, Secka O, Jaffar S, Greenwood BM. Vaccination with a Haemophilus influenzae type $b$ conjugate vaccine reduces oropharyngeal carriage of $H$. influenzae type $b$ among Gambian children. J Infect Dis 1998; 177(6): 1758-61.

[56] Moulton LH, Chung S, Croll J, Reid R, Weatherholtz RC, Santosham M. Estimation of the indirect effect of Haemophilus influenzae type $b$ conjugate vaccine in an American Indian population. Int J Epidemiol 2000; 29(4): 753-6.

[57] Murphy TV, Pastor P, Medley F, Osterholm MT, Granoff DM. Decreased Haemophilus colonization in children vaccinated with Haemophilus influenzae type b conjugate vaccine. J Pediatr 1993; 122(4): 517-23.
[58] Madhi SA, Petersen K, Khoosal M, et al. Reduced effectiveness of Haemophilus influenzae type $\mathrm{b}$ conjugate vaccine in children with a high prevalence of human immunodeficiency virus type 1 infection. Pediatr Infect Dis J 2002; 21(4): 315-321.

[59] Akumu AO, English M, Scott JA, Griffiths UK. Economic evaluation of delivering Haemophilus influenzae type $b$ vaccine in routine immunization services in Kenya. Bull World Health Organ 2007; 85(7): 511-8.

[60] Madhi SA, Petersen K, Madhi A, Wasas A, Klugman KP. Impact of human immunodeficiency virus type 1 on the disease spectrum of Streptococcus pneumoniae in South African children. Pediatr Infect Dis J 2000; 19(12): 1141-7.

[61] Bliss SJ, O'Brien KL, Janoff EN, et al. The evidence for using conjugate vaccines to protect $\mathrm{HIV}$-infected children against pneumococcal disease. Lancet Infect Dis 2008; 8(1): 67-80.

[62] Klugman KP, Madhi SA, Huebner RE, Kohberger R, Mbelle N, Pierce N. A trial of a 9-valent pneumococcal conjugate vaccine in children with and those without HIV infection. N Engl J Med 2003; 349(14): 1341-8

[63] Cutts FT, Zaman SM, Enwere G, et al. Efficacy of nine-valent pneumococcal conjugate vaccine against pneumonia and invasive pneumococcal disease in The Gambia. randomised, double-blind, placebo-controlled trial. Lancet 2005; 365(9465): 1139-46.

[64] Grijalva CG, Nuorti JP, Arbogast PG, Martin SW, Edwards KM, Griffin MR. Decline in pneumonia admissions after routine childhood immunisation with pneumococcal conjugate vaccine in the USA. a time-series analysis. Lancet 2007; 369(9568): 1179-86.

[65] Kyaw MH, Lynfield R, Schaffner W, et al. Effect of introduction of the pneumococcal conjugate vaccine on drug-resistant Streptococcus pneumoniae. N Engl J Med 2006; 354(14): 1455-63.

[66] Nachman S, Kim S, King J, et al. Safety and immunogenicity of a heptavalent pneumococcal conjugate vaccine in infants with human immunodeficiency virus type 1 infection. Pediatrics 2003; 112(1 Pt 1): 66-73.

[67] Madhi SA, Kuwanda L, Cutland C, Holm A, Kayhty H, Klugman KP. Quantitative and qualitative antibody response to pneumococcal conjugate vaccine among African human immunodeficiency virus-infected and uninfected children. Pediatr Infect Dis J 2005; 24(5): 410-6.

[68] Madhi SA, Kuwanda L, Cutland C, Klugman KP. The impact of a 9-valent pneumococcal conjugate vaccine on the public health burden of pneumonia in HIV-infected and -uninfected children. Clin Infect Dis 2005; 40(10): 1511-8.

[69] Singleton RJ, Hennessy TW, Bulkow LR, et al. Invasive pneumococcal disease caused by nonvaccine serotypes among alaska native children with high levels of 7-valent pneumococcal conjugate vaccine coverage. JAMA 2007; 297(16): 1784-92.

[70] Pelton SI, Huot H, Finkelstein JA, et al. Emergence of 19A as virulent and multidrug resistant Pneumococcus in Massachusetts following universal immunization of infants with pneumococcal conjugate vaccine. Pediatr Infect Dis J 2007; 26(6): 468-72.

[71] Barricarte A, Castilla J, Gil-Setas A, et al. Effectiveness of the 7valent pneumococcal conjugate vaccine. a population-based casecontrol study. Clin Infect Dis 2007; 44(11): 1436-41.

[72] Sinha A, Levine O, Knoll MD, Muhib F, Lieu TA. Costeffectiveness of pneumococcal conjugate vaccination in the prevention of child mortality. an international economic analysis. Lancet 2007; 369(9559): 389-96.

[73] Zar HJ. Prevention of HIV-associated respiratory illness in children in developing countries. potential benefits. Int J Tuberc Lung Dis 2003; 7(9): 820-7.

[74] Chintu C, Bhat GJ, Walker AS, et al. Co-trimoxazole as prophylaxis against opportunistic infections in HIV-infected Zambian children (CHAP). a double-blind randomised placebocontrolled trial. Lancet 2004; 364(9448): 1865-71.

[75] Guidelines for cotrimoxazole prophylaxis for HIV-related infection among children, adolescents and adults in rescource-limited settings. Recommendations for a public health approach. WHO 2006; [http/www.who.int/hiv/pub/guideline/ctx].

[76] American Academy of Pediatrics. Pickering LK, Ed. Red Book. 2009 report of the Committee on Infectious Diseases, $28^{\text {th }}$ ed. Elk Grove Village, IL: American Academy of Pediatrics 2009.

[77] Smieja MJ, Marchetti CA, Cook DJ, Smaill FM. Isoniazid for preventing tuberculosis in non-HIV infected persons. Cochrane Database Syst Rev 2000; (2): CD001363. 
[78] Woldehanna S, Volmink J. Treatment of latent tuberculosis infection in HIV infected persons. Cochrane Database Syst Rev 2004; (1): CD000171.

[79] Zar HJ, Cotton MF, Strauss S, et al. Effect of isoniazid prophylaxis on mortality and incidence of tuberculosis in children with HIV. randomised controlled trial. BMJ 2007; 334(7585): 136.

[80] Gray DM, Zar H. Cotton M. Impact of tuberculosis preventive therapy on tuberculosis and mortality in HIV-infected children. Cochrane Database Syst Rev 2009; (1): CD006418.

[81] Gray D, Nuttall J, Lombard C, et al. Low rates of hepatotoxicity in HIV-infected children on anti-retroviral therapy with and without isoniazid prophylaxis. J Trop Pediatr 2010; 56: 159-65.

[82] Gona P, Van Dyke RB, Williams PL, et al, Incidence of opportunistic and other infections in HIV-infected children in the HAART era. JAMA 2006; 296(3): 292-300.

[83] Walters E, Cotton MF, Rabie H, Schaaf HS, Walters LO, Marais BJ. Clinical presentation and outcome of tuberculosis in human immunodeficiency virus infected children on anti-retroviral therapy. BMC Pediatr 2008; 8: 1

[84] Violari A, Cotton MF, Gibb DM, et al. Early antiretroviral therapy and mortality among HIV-infected infants. N Engl J Med 2008; 359(21): 2233-44.

[85] WHO. Report of the WHO Technical Reference Group. Paediatric HIV/ART care guideline group meeting. Geneva: WHO 2008

[86] Sazawal S, Black RE. Effect of pneumonia case management on mortality in neonates, infants, and preschool children. a metaanalysis of community-based trials. Lancet Infect Dis 2003; 3(9): $547-56$.

[87] Kallander K, Tomson G, Nsabagasani X, Sabiiti JN, Pariyo G, Peterson S. Can community health workers and caretakers recognise pneumonia in children? Experiences from western Uganda. Trans R Soc Trop Med Hyg 2006; 100(10): 956-63.

[88] Winch PJ, Gilroy KE, Wolfheim C, et al. Intervention models for the management of children with signs of pneumonia or malaria by community health workers. Health Policy Plan 2005; 20(4): 199212

[89] Hazir T, Qazi S, Nisar YB, et al. Assessment and management of children aged 1-59 months presenting with wheeze, fast breathing, and/or lower chest indrawing; results of a multicentre descriptive study in Pakistan. Arch Dis Child 2004; 89(11) : 1049-54.

[90] Kallander K, Nsungwa-Sabiiti J, Balyeku A, Pariyo G, Tomson G, Peterson S. Home and community management of acute respiratory infections in children in eight Ugandan districts. Ann Trop Paediatr 2005; 25(4): 283-91

[91] Marsh DR, Gilroy KE, Van de Weerdt R, Wansi E, Qazi S. Community case management of pneumonia. at a tipping point? Bull World Health Organ 2008; 86(5): 381-9.

[92] Reyes H, Perez-Cuevas R, Salmeron J, Tome P, Guiscafre H, Gutierrez G. Infant mortality due to acute respiratory infections. the influence of primary care processes. Health Policy Plan 1997; 12(3): 214-23.

[93] Kallander K, Hildenwall H, Waiswa P, Galiwango E, Peterson S, Pariyo G. Delayed care seeking for fatal pneumonia in children aged under five years in Uganda. a case-series study. Bull World Health Organ 2008; 86(5): 332-8.

[94] English M, Esamai F, Wasunna A, et al. Assessment of inpatient paediatric care in first referral level hospitals in 13 districts in Kenya. Lancet 2004; 363(9425): 1948-53

[95] Nolan T, Angos P, Cunha AJ, et al. Quality of hospital care for seriously ill children in less-developed countries. Lancet 2001; 357(9250): 106-10.

[96] Berkley JA, Maitland K, Mwangi I, et al. Use of clinical syndromes to target antibiotic prescribing in seriously ill children in malaria endemic area. observational study. BMJ 2005; 330(7498): 995

[97] Enarson PM, Gie R, Enarson DA, Mwansambo C. Development and implementation of a national programme for the management of severe and very severe pneumonia in children in Malawi. PLoS Med 2009; 6(11): e1000137.

[98] WHO. Technical updates of the guidelines on the management of childhood illness (IMCI). Evidence and recommendationsfor further adaptations. Geneva: WHO 2005.

[99] Fonseca W, Hoppu K, Rey LC, Amaral J, Qazi S. Comparing pharmacokinetics of amoxicillin given twice or three times per day to children older than 3 months with pneumonia. Antimicrob Agents Chemother 2003; 47(3): 997-1001.
[100] Awasthi S, Agarwal G, Singh JV, et al. Effectiveness of 3-day amoxycillin $v s 5$-day co-trimoxazole in the treatment of non-severe pneumonia in children aged 2-59 months of age. a multi-centric open labeled trial. J Trop Pediatr 2008; 54(6): 382-9.

[101] Catchup Study Group. Clinical efficacy of co-trimoxazole versus amoxicillin twice daily for treatment of pneumonia. a randomised controlled clinical trial in Pakistan. Arch Dis Child 2002; 86(2): $113-18$

[102] Straus WL, Qazi SA, Kundi Z, Nomani NK, Schwartz B. Antimicrobial resistance and clinical effectiveness of cotrimoxazole versus amoxycillin for pneumonia among children in Pakistan. randomised controlled trial. Pakistan Co-trimoxazole Study Group. Lancet 1998; 352(9124): 270-4.

[103] Clinical efficacy of 3 days versus 5 days of oral amoxicillin for treatment of childhood pneumonia. a multicentre double-blind trial. Lancet 2002; 360(9336): 835-41.

[104] Agarwal S, Awasthi S, Kabra SK, Kaul A, Singhi S, Walter SD; ISCAP Study Group. Three day versus five day treatment with amoxicillin for non-severe pneumonia in young children. a multicentre randomised controlled trial. BMJ 2004; 328: 791-4.

[105] Nascimento-Carvalho CM, Ribeiro CT, Cardoso MR, et al. The role of respiratory viral infections among children hospitalized for community-acquired pneumonia in a developing country. Pediatr Infect Dis J 2008; 27(10): 939-41.

[106] Ayieko P, English M. Case management of childhood pneumonia in developing countries. Pediatr Infect Dis J 2007; 26(5): 432-40.

[107] Shann F, Hart K, Thomas D. Acute lower respiratory tract infections in children. possible criteria for selection of patients for antibiotic therapy and hospital admission. Bull World Health Organ 1984; 62: 749-53.

[108] Campbell H, Byass P, Lamont AC, et al. Assessment of clinical criteria for identification of severe acute lower respiratory tract infections in children. Lancet 1989; 1(8633): 297-9.

[109] Cherian T, John TJ, Simoes E, Steinhoff MC, John M. Evaluation of simple clinical signs for the diagnosis of acute lower respiratory tract infection. Lancet 1988; 2(8603): 125-8.

[110] Usen S, Webert M. Clinical signs of hypoxaemia in children with acute lower respiratory infection. indicators of oxygen therapy. Int J Tuberc Lung Dis 2001; 5(6): 505-10.

[111] Subhi R, Adamson M, Campbell H, Weber M, Smith K, Duke T. The prevalence of hypoxaemia among ill children in developing countries. a systematic review. Lancet Infect Dis 2009; 9(4): 21927.

[112] Duke T, Mgone J, Frank D. Hypoxaemia in children with severe pneumonia in Papua New Guinea. Int J Tuberc Lung Dis 2001; 5(6): 511-9.

[113] Usen S, Weber M, Mulholland K, et al. Clinical predictors of hypoxaemia in Gambian children with acute lower respiratory tract infection. prospective cohort study. BMJ 1999; 318(7176): 86-91

[114] Weber MW, Usen S, Palmer A, Jaffar S, Mulholland EK. Predictors of hypoxaemia in hospital admissions with acute lower respiratory tract infection in a developing country. Arch Dis Child 1997; 76(4): 310-4.

[115] Lodha R, Bhadauria PS, Kuttikat AV, et al. Can clinical symptoms or signs accurately predict hypoxemia in children with acute lower respiratory tract infections? Indian Pediatr 2004; 41(2): 129-35.

[116] Laman M, Ripa P, Vince J, Tefuarani N. Can clinical signs predict hypoxaemia in Papua New Guinean children with moderate and severe pneumonia? Ann Trop Paediatr 2005; 25(1): 23-7.

[117] Onyango FE, Steinhoff MC, Wafula EM, Wariua S, Musia J, Kitonyi J. Hypoxaemia in young Kenyan children with acute lower respiratory infection. BMJ 1993; 306(6878): 612-5.

[118] Ayieko P, English M. In children aged 2-59 months with pneumonia, which clinical signs best predict hypoxaemia? J Trop Pediatr 2006; 52(5): 307-10.

[119] Duke T, Wandi F, Jonathan M, et al. Improved oxygen systems for childhood pneumonia. a multihospital effectiveness study in Papua New Guinea. Lancet 2008; 372(9646): 1328-33

[120] Steinhoff M, Black R. Childhood pneumonia. we must move forward. Lancet 2007; 369(9571): 1409-10.

[121] Matai S, Peel D, Wandi F, Jonathan M, Subhi R, Duke T. Implementing an oxygen programme in hospitals in Papua New Guinea. Ann Trop Paediatr 2008; 28(1): 71-8.

[122] Shann F, Barker J, Poore P. Chloramphenicol alone versus chloramphenicol plus penicillin for bacterial meningitis in children. Lancet 1985; 2(8457): 681-4. 
[123] Duke T, Poka H, Dale F, Michael A, Mgone J, Wal T. Chloramphenicol versus benzylpenicillin and gentamicin for the treatment of severe pneumonia in children in Papua New Guinea. a randomised trial. Lancet 2002; 359(9305): 474-80.

[124] Asghar R, Banajeh S, Egas J, et al. Chloramphenicol versus ampicillin plus gentamicin for community acquired very severe pneumonia among children aged 2-59 months in low resource settings. multicentre randomised controlled trial (SPEAR study). BMJ 2008; 336(7635): 80-4.

[125] Cardoso MR, Nascimento-Carvalho CM, Ferrero F, et al. Penicillin-resistant pneumococcus and risk of treatment failure in pneumonia. Arch Dis Child 2008; 93(3): 221-5.

[126] Addo-Yobo E, Chisaka N, Hassan M, et al. Oral amoxicillin versus injectable penicillin for severe pneumonia in children aged 3 to 59 months. a randomised multicentre equivalency study. Lancet 2004; 364(9440): 1141-8.

[127] Hazir T, Fox LM, Nisar YB, et al. Ambulatory short-course highdose oral amoxicillin for treatment of severe pneumonia in children. a randomised equivalency trial. Lancet 2008; 371(9606): 49-56.
[128] Agarwal G, Awasthi S, Kabra SK, Kaul A, Singhi S, Walter SD. Three day versus five day treatment with amoxicillin for nonsevere pneumonia in young children. a multicentre randomised controlled trial. BMJ 2004; 328(7443): 791.

[129] Fu LY, Ruthazer R, Wilson I, et al. Brief hospitalization and pulse oximetry for predicting amoxicillin treatment failure in children with severe pneumonia. Pediatrics 2006; 118(6): e1822-30.

[130] Tiewsoh K, Lodha R, Pandey RM, Broor S, Kalaivani M, Kabra SK. Factors determining the outcome of children hospitalized with severe pneumonia. BMC Pediatr 2009; 9: 15.

[131] Patel A, Mamtani M, Hibberd PL, et al. Value of chest radiography in predicting treatment response in children aged 3-59 months with severe pneumonia. Int J Tuberc Lung Dis 2008; 12(11): 1320-6.

[132] Mamtani M, Patel A, Hibberd PL, et al. A clinical tool to predict failed response to therapy in children with severe pneumonia. Pediatr Pulmonol 2009; 44(4): 379-86.

[133] WHO. Management of the child with a serious infection or severe malnutrition. Guidelines for care at first-referral level in developing countries. WHO: Geneva 2000.

(C) Gray and Zar; Licensee Bentham Open.

This is an open access article licensed under the terms of the Creative Commons Attribution Non-Commercial License (http://creativecommons.org/licenses/ by-nc/3.0/) which permits unrestricted, non-commercial use, distribution and reproduction in any medium, provided the work is properly cited. 